www.jmscr.igmpublication.org

Impact Factor 5.84

Index Copernicus Value: 83.27

ISSN (e)-2347-176x ISSN (p) 2455-0450

crossref DOI: https://dx.doi.org/10.18535/jmscr/v5i2.97

\title{
Predictive Equation for Height Estimation in Egyptian Elderly Females
}

\author{
Authors \\ Hala Samir Sweed ${ }^{1}$, Heba Youssif Kamel², Sally Maher Adly ${ }^{3}$, \\ Nahla Fawzy Abou El Ezz ${ }^{4}$, Hazem Mohammed El-Hariri ${ }^{5}$ \\ ${ }^{1}$ Professor of Geriatric Medicine \& Gerontology, Ain Shams University, Cairo, Egypt \\ ${ }^{2}$ Lecturer of Geriatric Medicine \& Gerontology, Ain Shams University, Cairo, Egypt \\ ${ }^{3}$ Postgraduate Student of Geriatric Medicine \& Gerontology, Ain Shams University, Cairo, Egypt \\ ${ }^{4}$ Assistant Professor of Community, Environment \& Occupational Medicine, Ain Shams University, Cairo, \\ Egypt \\ ${ }^{5}$ Assistant Researcher of Community Medicine Research, National Research Center, Cairo, Egypt \\ Corresponding Author
}

Heba Youssif Kamel

Department of Geriatric Medicine \& Gerontology, Ain Shams University,

Khalifa Almamoon Street, Abbasiya, Cairo 11566, Egypt

Telephone: 0020167995991, Email: heba_youssif@yahoo.com

\begin{abstract}
:
Introduction: Height, one of anthropometric measurements, is a very important indicator of body size for use in clinical setting, nutrition and health research. However, height is difficult to measure in nonambulatory elderly person and in those elderly persons with excessive spinal curvature. Also, the accuracy of the equations is reduced if used to estimate stature in populations in which the equation has not been derived from as all these anthropometric parameters are being influenced by many genetic, environmental and biological factors.
\end{abstract}

Aim of work: this study was conducted it to develop sex-specific equation for height estimation among Egyptian elderly females and to assess the most accurate method for estimation of height in Egyptian elderly females from 3 anthropometric parameters; demi-span, ulnar length and knee height, and to use it to develop sex-specific equation for height estimation among Egyptian elderly females.

Patient and Methods: A cross sectional study in outpatient Geriatric clinic of Ain Shams university hospitals, done on 226 community dwelling elderly females (60 years old and above). The following parameters (knee height, ulnar length, demi span) were measured and integrated into specific predictive equations and compared with the height of the participants through statistical analysis.

Results: This study showed that there are significant positive correlations between standing height and other anthropometric measurements as knee height, demi-span and ulnar length with Pearson correlation coefficient ( $r=0.814,0.739$ and 0.662 respectively).

Conclusion: The correlation with knee height was found to be stronger than those with demi span and ulnar length.

Keywords: Anthropometric measurements, Egyptian elderly, demi-span, ulnar length, knee height, Predictive Equation. 


\section{Introduction}

Height, one of the anthropometric measurements, is indeed a very important indicator of body size for use in the clinical setting and also for nutrition and health research ${ }^{[1]}$.

Together with body weight, height is used in calculation of body mass index (BMI) in nutritional assessment, creatinine height index which shows protein nutrition, resting energy expenditure from the Harris-Benedict's equation, basal metabolic rate $^{[2]}$, estimation of nutrient requirements and calculation of body composition such as fat free mass ${ }^{[3]}$. Height is also necessary for calculation of body surface area for drug dosage adjustment ${ }^{[4]}$ and estimation of renal clearance ${ }^{[5]}$.Height is used in predicting lung volumes, which are used in pulmonary function tests ${ }^{[6]}$.

However, there are difficulties in obtaining an accurate measurement of height in elderly subjects. Ageing is associated with several physiological, psychological and biological changes, including body composition, such as an increase in body fat and a decrease in lean body mass and also bone mass $^{[7]}$. This can lead to changes in body posture and thinning of vertebrae and discs which can contribute to a reduction in height ${ }^{[8]}$ or even kyphosis in elderly people with osteoporosis ${ }^{[9]}$.

Standing height is also rather difficult to measure in elderly subjects due to several conditions such as infectious diseases, arthritis, paralysis and amputation $^{[10]}$.

So measurements of other body segments such as knee height, arm span, demi-span and ulnar length have been proposed as alternative methods for predicting height in elderly people because the length of long bones is less affected by ageing ${ }^{[11]}$.

So the aim of this study is to assess the most accurate method for estimation of height in Egyptian elderly females from the 3 anthropometric parameters; demi-span, ulnar length and knee height, and to use it to develop sex-specific equation for height estimation among Egyptian elderly females.

\section{Methods}

\section{Patients}

A cross sectional study consisted of 226 community dwelling elderly females (60 years old and above) attending the outpatient Geriatric clinic of Ain Shams university hospitals. The sample size was calculated using Epi-info 2002 program. The included patients were ambulant, able to stand erect without spinal curvature and able to spread left arm straight perpendicular to the body; but those with a plaster cast, a prosthetic, amputated, or edematous limb or with frozen shoulder, kyphosis, bed or chair-bound individuals were excluded from the study. This study had the approval of the ethics committee of the Ain Shams Faculty of Medicine. All subjects consented to participate in the study.

\section{Methods}

Full medical history and examination were done. Measuring standing height barefoot in an upright posture looking forward with the informant stretching to the maximum height and head in the Frankfort horizontal plane, with heels together, arms at the side, legs straight, shoulders relaxed and with heels, buttocks, scapulae and back of the head lying against a vertical wall or a door.

Measuring the following parameters which were integrated into specific predictive equations and compared with the height of the participants through statistical analysis:

\section{Knee height:}

It was measured with the subject in the seated position. It is the distance from the sole of the foot to the anterior surface of the thigh with ankle and knee each flexed to a 90 degree angle ${ }^{[12]}$.

\section{Ulnar length:}

This was measured with the left arm bent up across the chest, with the palm flat across the chest and fingers pointing to the opposite shoulder. The length from the point of the elbow (the olecranon) to the mid-point of the prominent bone of the wrist (the styloid process) is then measured.

\section{Demi-span:}

This was measured with the left arm outstretched straight, palm forwards, from the base of the middle/ ring fingers to the sternal notch using a nonstretch tape measure ${ }^{[13]}$. 
All measurements were taken by using a metal retractable tape, taken to the nearest millimeter and recorded by the same person to minimize the errors in methodology.

\section{Statistical methodology}

The collected data were coded, tabulated, and statistically analyzed using IBM SPSS statistics (Statistical Package for Social Sciences) (V. 22.0) software version 22.0, IBM Corp., Chicago, USA, 2013.

Descriptive statistics were done for quantitative data as minimum\& maximum of the range as well as mean \pm SD (standard deviation) for quantitative parametric data, while it was done for qualitative data as number and percentage.

Inferential analyses were done for quantitative variables using independent t-test in cases of two independent groups with parametric data and paired t-test in cases of two dependent groups with parametric data. Correlations were done using Pearson Correlation. Linear regression model was used to find out independent factors affecting standing height.

The level of significance was taken at $\mathrm{P}$ value < 0.05 is significant, otherwise is non-significant. The p-value is a statistical measure for the probability that the results observed in a study could have occurred by chance.

\section{Results}

The demographic data of the study population showed that $78.4 \%$ of the studied cases were less

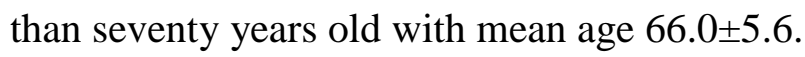

Table (1) shows the Mean \pm SD and range of standing height, knee height, demi-span and ulnar length of the studied subjects.

There were wave like correlations between age and different height measurements, the cycles were variable in length. Decreases from 60.0 to 62.0 years (1955 - 1953 births), then rises until 65.0 year (1950 births), then decreases till 70.0 year (1945 births) to raise till 80.0 year (1935 births) and final decrease till 85.0 year (1930 births).

It was found that there were significant positive linear correlations between measured standing height and the 3 studied anthropometric measure- ments with $\mathrm{P}<0.001$ for each. The correlation with knee height was stronger than those with demi span and ulnar length with $\mathrm{r}=0.814,0.739$ and 0.662 respectively (Table 1) and (figure1).

Then knee height was used to estimate height of Egyptian elderly females using equations developed from other populations such as Malaysian, Mexican, Korean, Swedish, Hispanics, black American, white American and Puerto Ricans. There was significant difference between measured standing height and predicted height where predicted height using Swedish, Malaysian, black American and Mexican American equations was found to be statistically significantly higher than measured standing height while predicted height from Mexican, Korean, Hispanic, Puerto Rican and white American equations was found to be statistically significantly lower than measured standing height.The differences may be due to variation in body composition and stature among ethnic groups, i.e. tall versus short statured populations(Table 2).

\section{Equations used for height prediction:}

$1-$ Mexican ${ }^{[14]}$ :Height $=55.6+2.03$ (Knee height)

2- Malaysian ${ }^{[1]}:$ Height $=50.25+2.225$ (Knee height)

3 - Korean ${ }^{[15]}$ :Height $=70.87-(0.14$ age $)+(1.96$ knee height)

4- Sweden ${ }^{[16]}$ : Height $=104.52+(1.23$ knee height $)$

5- Hispanic ${ }^{[10]}$ : Height $=68.68+(1.90$ knee height $)$ $-(0.123$ age $)$

6- Puerto Rican ${ }^{[10]}$ : Height $=55.98+(1.99$ knee height)

7- Non-Hispanic White women ${ }^{[17]}$ : Height $=82.21+$ (1.85 knee height) - (0.21age)

8- Non-Hispanic Black women ${ }^{[17]}$ : Height $=89.58+$ (1.61 knee height $)-(0.17$ age $)$

9- Mexican-American ${ }^{[17]}$ : Height $=84.25+$ (1. 82 knee height $)$ - (0.26age)

So a gender- and population-specific equation was developed for accurate estimation of height in Egyptian elderly females.

An estimation equation for stature was developed according to a simple regression analysis $[y=a+b$ $\mathrm{x}]$ where "y" represented predicted stature (dependent variable), "x" represented knee height (independent variable), "a" represented the constant 
(intercept) and "b" represented the regression coefficient (slope) of knee height.

And the Suggested model [Height $=53.781+2.131$ (Knee height)] was found to be significant with $\mathrm{P}$ $<0.001$ and $\mathrm{R}^{2}=66.3 \%$ which is interpreted as the proportion of the total variation in height accounted for by the factors of the equation which means that knee height and the constant explain $66.3 \%\left(\mathrm{R}^{2}\right)$ of the variability of stature (Table 3 ).

There was a strong significant positive correlation between measured and study predicted standing heights with $\mathrm{P}<0.001$ (Table 3 ).

There is no significant difference between measured standing height and height predicted from the prediction equation of this study with difference equals $0.0 \pm 3.4 \mathrm{~cm}$ (Table 2).

Table (1): Correlation between standing height and other height measurements $(\mathrm{cm})$

\begin{tabular}{|l|c|c|c|c|}
\hline Height & Mean \pm SD & Range & $\mathrm{r}$ & $\mathrm{P}$ \\
\hline Standing & $153.9 \pm 6.0$ & $141.0-169.0$ & & \\
\hline Knee & $47.0 \pm 2.3$ & $42.0-54.0$ & 0.814 & $<0.001^{*}$ \\
\hline Demi-span & $72.1 \pm 3.2$ & $63.0-80.0$ & 0.739 & $<0.001^{*}$ \\
\hline Ulna & $24.7 \pm 1.2$ & $22.0-27.0$ & 0.662 & $<0.001^{*}$ \\
\hline
\end{tabular}

$\mathrm{r}=$ Pearson correlation coefficient, $*$ Significant

Table (3): Linear regression for prediction of standing height

\begin{tabular}{|l|c|c|c|c|c|}
\hline & $\mathrm{B}$ & $\mathrm{SE}$ & $\mathrm{P}$ & $95 \% \mathrm{CI}$ & $\mathrm{R}^{2}$ \\
\hline Constant & 53.781 & 4.775 & $<0.001^{*}$ & $44.372-63.190$ & \multirow{2}{*}{0.663} \\
\cline { 1 - 5 } $\begin{array}{l}\text { Knee } \\
(\mathrm{cm})\end{array}$ & 2.131 & 0.102 & $<0.001^{*}$ & $1.931-2.331$ & \\
\hline
\end{tabular}

$\beta$ : Regression coefficient, SE: Standard error, CI: Confidence interval,

$\mathrm{R}^{2}$ : Coefficient of determination, *: Significant

\section{Discussion}

Our study agreed with many previous studies where it was found that Knee height presented a very high correlation with height in different countries. Mette and his colleagues ${ }^{[18]}$ conducted a study on twohundred and fifty patients (157 men/93 women) aged $61 \pm 15$ years. The study aimed at comparing the stature estimation using the Chumlea equation of knee height with metric determination in critically ill patients at all ages, and at determining the feasibility of such a determination in an ICU. The mean difference between ribbon measured height and calculated stature from knee height was $-1.1 \pm$ $5.3 \mathrm{~cm}$ and the correlation between measured and calculated stature was fair (r $2=0.664, \mathrm{p}<0.001$ ). Mette and his colleagues concluded that knee height measurement was rapid and easy and enabled determination of ICU patient stature and that the Chumlea equation was a reasonably accurate tool to determine height and derived values in ICU patients.

Table (2): Comparison between measured standing height and predicted height $(\mathrm{cm})$ using measured knee height in equations developed fromother populations and equation from this study

\begin{tabular}{|c|c|c|c|c|}
\hline & & Measurement & Difference & $\mathrm{P}$ \\
\hline \multirow{3}{*}{$\begin{array}{l}\text { Measured } \\
\text { standing height }\end{array}$} & Mean \pm SD & $153.9 \pm 6.0$ & -- & \\
\hline & Range & $141.0-169.0$ & -- & \\
\hline & $95 \% \mathrm{CI}$ & $154.2-155.7$ & & \\
\hline \multirow{3}{*}{$\begin{array}{l}\text { Predicted height } \\
\text { from Mexican } \\
\text { equation }\end{array}$} & Mean \pm SD & $150.9 \pm 4.6$ & $2.9 \pm 3.4$ & \multirow{3}{*}{$<0.001 *$} \\
\hline & Range & $140.9-165.2$ & $-7.0-13.0$ & \\
\hline & $95 \% \mathrm{CI}$ & $154.4-155.6$ & $2.3-3.6$ & \\
\hline \multirow{3}{*}{$\begin{array}{l}\text { Predicted height } \\
\text { from Malaysian } \\
\text { equation }\end{array}$} & Mean \pm SD & $154.7 \pm 5.0$ & $-0.9 \pm 3.4$ & \multirow{3}{*}{$<0.001 *$} \\
\hline & Range & $143.7-170.4$ & $-10.7-8.9$ & \\
\hline & $95 \% \mathrm{CI}$ & $154.1-155.4$ & $-1.5--0.2$ & \\
\hline \multirow{3}{*}{$\begin{array}{lr}\text { Predicted } & \text { height } \\
\text { from } & \text { Korean } \\
\text { equation } & \end{array}$} & Mean \pm SD & $153.7 \pm 4.6$ & $1.3 \pm 4.9$ & \multirow{3}{*}{$<0.001 *$} \\
\hline & Range & $143.4-168.0$ & $-19.0-19.0$ & \\
\hline & $95 \% \mathrm{CI}$ & $153.1-154.3$ & $0.6-1.9$ & \\
\hline \multirow{3}{*}{$\begin{array}{l}\text { Predicted height } \\
\text { from Swedish } \\
\text { equation }\end{array}$} & Mean \pm SD & $162.3 \pm 2.8$ & $-7.4 \pm 4.8$ & \multirow{3}{*}{$<0.001^{*}$} \\
\hline & Range & $156.2-170.9$ & $-23.5-8.4$ & \\
\hline & $95 \% \mathrm{CI}$ & $161.9-162.6$ & $-8.0--6.7$ & \\
\hline \multirow{3}{*}{$\begin{array}{l}\text { Predicted height } \\
\text { from Hispanic } \\
\text { equation }\end{array}$} & Mean \pm SD & $149.8 \pm 4.5$ & $5.1 \pm 4.8$ & \multirow{3}{*}{$<0.001^{*}$} \\
\hline & Range & $139.9-163.7$ & $-14.7-22.7$ & \\
\hline & $95 \% \mathrm{CI}$ & $149.2-150.4$ & $4.5-5.8$ & \\
\hline \multirow{3}{*}{$\begin{array}{l}\text { Predicted height } \\
\text { from Puerto } \\
\text { Rican equation }\end{array}$} & Mean \pm SD & $149.4 \pm 4.5$ & $5.5 \pm 4.9$ & \multirow{3}{*}{$<0.001 *$} \\
\hline & Range & $139.6-163.4$ & $-14.4-23.5$ & \\
\hline & $95 \% \mathrm{CI}$ & $148.8-150.0$ & $4.8-6.1$ & \\
\hline \multirow{3}{*}{$\begin{array}{l}\text { Predicted height } \\
\text { from } \\
\text { American }\end{array}$} & Mean \pm SD & $155.2 \pm 4.5$ & $0.3 \pm 4.8$ & \multirow{3}{*}{$<0.001^{*}$} \\
\hline & Range & $145.2-169.1$ & $-17.0-20.1$ & \\
\hline & $95 \% \mathrm{CI}$ & $154.6-155.8$ & $-0.3-0.9$ & \\
\hline \multirow{3}{*}{$\begin{array}{lr}\text { Predicted } & \text { height } \\
\text { from } & \text { black } \\
\text { American } & \end{array}$} & Mean \pm SD & $153.6 \pm 3.9$ & $-1.3 \pm 4.7$ & \multirow{3}{*}{$<0.001 *$} \\
\hline & Range & $145.0-165.7$ & $-18.0-16.7$ & \\
\hline & $95 \% \mathrm{CI}$ & $153.1-154.1$ & $-1.9--0.7$ & \\
\hline \multirow{3}{*}{$\begin{array}{l}\text { Predicted height } \\
\text { from Mexican } \\
\text { American } \\
\text { equation }\end{array}$} & Mean \pm SD & $152.6 \pm 4.6$ & $-2.4 \pm 4.8$ & \multirow{3}{*}{$<0.001^{*}$} \\
\hline & Range & $141.8-166.4$ & $-19.6-17.4$ & \\
\hline & $95 \% \mathrm{CI}$ & $152.0-153.2$ & $-3.0--1.7$ & \\
\hline \multirow{3}{*}{$\begin{array}{l}\text { Study predicted } \\
\text { height }\end{array}$} & Mean \pm SD & $153.8 \pm 4.8$ & $0.0 \pm 3.4$ & \multirow{3}{*}{0.989} \\
\hline & Range & $143.3-168.9$ & $-9.9-9.9$ & \\
\hline & $95 \% \mathrm{CI}$ & $153.2-154.5$ & $-0.6-0.6$ & \\
\hline
\end{tabular}

Difference: Actual - predicted, P: P-value of Paired t-test, *: Significant, CI: Confidence interval, Study equation: Height $=53.781+2.131$ (Knee height) 

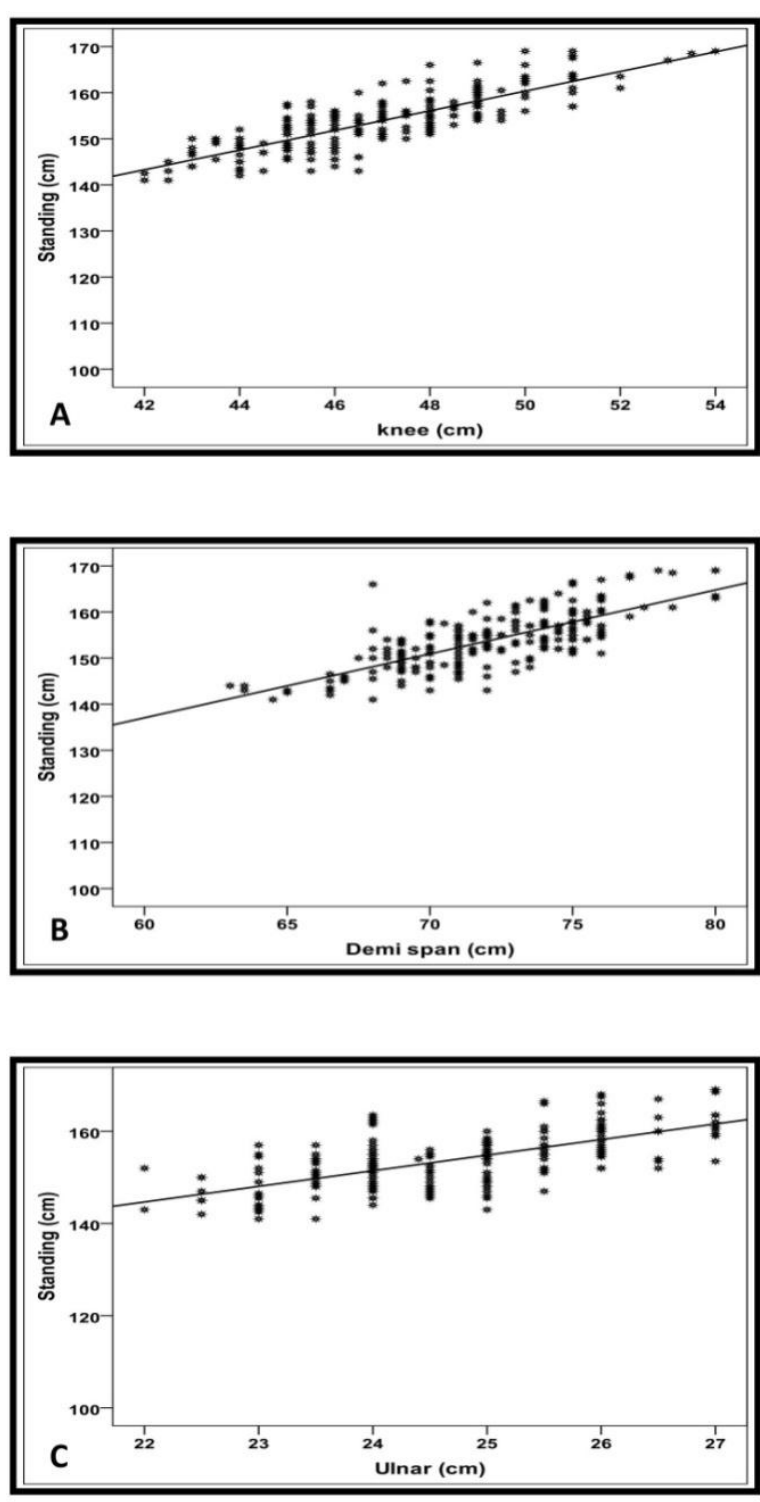

Fig.1 A: Correlation between standing and knee heights; B: Correlation between standing and demi span heights; C: Correlation between standing and ulnar heights.

So gender specific equation was developed by simple linear regression to predict stature from knee height alone for use amongst Egyptian elderly females and the suggested model is $[$ Height $=53.781+2.131($ Knee height $)]$. The height predicted from this equation ranged from 143.3$168.9 \mathrm{~cm}$ with mean $153.8 \pm \mathrm{SD} 4.8 \mathrm{~cm}$. Age was not used in the equation because this study showed that there was no linear correlation between age and height.

The measurement of knee height provides a simple, quick, and accurate means in estimating stature for the elderly, whose height cannot be measured because it is easy to measure in either a sitting or a recumbent position in almost all elderly persons, regardless of their mobility status, and it is suitable in elderly persons with spinal deformities.

So new knee height equation for predicting height was introduced by the current study is recommended to be used in Egyptian elderly females because the other equations are not applicable as they are derived from other populations with different body compositions.

However, the limitation of this study is that the developed equation may not be applicable in the future if secular changes in height occurred among the Egyptian population, so then another equation must be developed for accurate estimation of height. Since that $78.4 \%$ of the studied cases were under seventy years old with mean age $66.0 \pm 5.6$ and estimates from longitudinal studies show that loss of height of up to $5 \mathrm{~cm}$ in men and $8 \mathrm{~cm}$ in women occurs from the age of 30 to 80 years ${ }^{[19]}$. So other studies are needed to assess the applicability of this newly developed equation on those above the age of 70 years old.

\section{References}

1. Shahar S, Pooy NS. Predictive equations for estimation of stature in Malaysian elderly people. Asia Pacific J Clin Nutr 2003; 12 (1):80-84.

2. McPherson JR, Lancaster DR, Carroll JC. Stature change with aging in Black Americans. J Gerontology1978;33(1):20-25.

3. Kyle UG, Bosaeus I, De Lorenzo AD, et al. Bioelectrical impedance analysis - part I: review of principles and methods. Clin Nutr 2004;23(5):1226-1243.

4. Sawyer M, Ratain MJ. Body surface area as a determinant of pharmacokinetics and drug dosing. Invest New Drugs 2001; 19(2):171177.

5. Peters AM, Henderson BL, Lui D. Indexed glomerular filtration rate as a function of age and body size. Clin Sci 2000;98(4):439-444.

6. Singh R, Singh HJ, Sirisinghe RG. Spirometric studies in Malaysians between 
13 and 69 years of age. Med J Malaysia 1993;48(2):175-184.

7. Kuchmarski RJ. Need for body composition information in elderly subjects. Am J Clin Nutr 1989;50:1150-1157.

8. Prothro JW, Rosenbloom CA. Physical measurements in an elderly black population: knee height as the dominant indicator of stature. J Gerontology 1993; 48 (1):15-18.

9. Roubenoff R, Wilson PWF. Advantage of knee height over height as an index of stature in expression of body composition in adults. Am J Clin Nutr 1993;57:609-613.

10. Bermudez OI, Becker EK, Tucker KL. Development of sex- specific equations for estimating stature of frail elderly Hispanic living in the North Eastern United States. Am J Clin Nutr 1999;69:992-998.

11. Mitchell CO, Lipschitz DA. Detection of protein-calorie malnutrition in the elderly. Am J Clin Nutr 1982;35:398-406.

12. Chumlea WC, Roche AF, Steinbaugh ML. Estimating stature from knee height for persons 60-90 years of age. J Am Geriatr Soc 1985;33:116-120.

13. Bassey EJ. Demi span as a measure of skeletal size. Ann Hum Biol 1986;13(5): 499-502.

14. Nunez VMM, Rodriguez MAS, Sandoval AC. Equations for predicting height for Elderly Mexican Americans Are Not Applicable for elderly Mexicans. American Journal of Human Biology 2002; 14:351355.

15. Hwang IC, Kim KK, Kang HC, et al. Validity of Stature predicted Equations using Knee Height for Elderly and Mobility Impaired Persons in Koreans. Epidemiol Health. 2009;31:e2009004.

16. Gavriilidou, NN, Pihlsgård M, Elmståhl, S. High degree of BMI misclassification of malnutrition among Swedish elderly population: Age-adjusted height estimation using knee height and demispan. European Journal of Clinical Nutrition 2014; 69(5):565-571.
17. Chumlea WC, Guo S, Wholihan K, et al. Stature prediction equations for elderly nonHispanic white, non-Hispanic black and Mexican-American persons developed from NHANES III data. J Am Diet Assoc 1998;98:137-142.

18. Mette MB, Marie-Christine C, Marie-Denise $\mathrm{S}$, et al. Stature estimation using the knee height determination in critically ill patients. European Society for clinical nutrition and metabolism 2008;3(2): e84-e88.

19. Sorkin JD, Muller DC, Andres R. Longitudinal change in the heights of men and women: consequential effects on body mass index. Epidemiol Rev 1999; 21(2):247-260. 